\title{
TRANSITION ROADMAP FOR THE ENERGY INFRASTRUCTURE IN THE NETHERLANDS - DEVELOPMENT OF INTEGRATING TOOLS BASED ON A MULTIDISCIPLINARY APPROACH
}

\author{
Greet M.A. VANALME \\ University of Technology \\ Eindhoven - The Netherlands \\ g.m.a.vanalme@tue.nl \\ Jasper VAN CASTEREN \\ KEMA - The Netherlands \\ jasper.vanCasteren@ \\ kema.com
}

\author{
Rob F.T. AALBERS \\ $\mathrm{CPB}-$ \\ The Netherlands \\ r.f.t.aalbers@cpb.nl
Gabriël A. BLOEMHOF
KEMA - The Netherlands gabriel.bloemhof@ \\ kema.com
}

\author{
Arie TEN CATE \\ $\mathrm{CPB}$ - \\ The Netherlands \\ a.ten.cate@cpb.nl \\ Martijn BONGAERTS \\ Alliander - The Netherlands \\ martijn.bongaerts@ \\ alliander.com
}

\author{
Johanna M.A. MYRZIK \\ University of Technology \\ Eindhoven - The Netherlands \\ j.m.a.myrzik@tue.nl \\ Geert J.P. VERBONG \\ University of Technology \\ Eindhoven - The Netherlands \\ g.j.p.verbong@tue.nl
}

\begin{abstract}
Energy systems have technical, economical and social dimensions. Thorough transition studies require an integral approach, dealing with all these aspects. In order to facilitate the studies and accelerate the transition to a renewable energy system, new integrating tools, based on a multidisciplinary approach, will be developed. This paper describes the concept for the integrating tools.
\end{abstract}

\section{INTRODUCTION}

The future energy infrastructure will have to be able to takein large quantities of renewable energy, whether large scale or distributed generation. These sources are characterized by a high degree of unpredictability. This might create severe problems and challenges for the electricity system and it can hamper the diffusion of renewable energy technologies. There are several options to prevent this, like adding stable compensating sources or by influencing consumer behaviour. With current analytical approaches it is not possible to show the effects on complex infrastructures like energy systems, which are affected by the availability of energy sources and technical possibilities, and are subject to the behaviour of several stakeholders (government, regulators, network companies, customers,...) with different goals. Behaviour does play a significant role [1] and may be sensitive to incentives (e.g. subsidies on investments [2]). Therefore an integral approach, combining technical, economic and social aspects, has to be developed and tested in laboratory and real-life experiments.

Within the Dutch EOS-LT research program a project is set up to deal with these issues. The problem statement is: What is the effect of distributed generation on the existing and future energy system (gas + electricity + heat), and how can experiments be selected and designed to accelerate the transition to a renewable energy system? The combined technical, economical and social expertise of the project consortium (TU/e, KEMA, Alliander, Gasunie, CPB, UvA) will develop new integrating tools for this.
This paper describes the concept for the integrating tools. Scenarios for possible transition paths for the energy infrastructure of a Dutch residential area are proposed. The approach for the economic optimization and technical feasibility study of the electricity infrastructure of the residential area is explained in more detail.

\section{CONCEPT INTEGRATING TOOLS}

Figure 1 gives a schematic overview of the different parts of the integrating tools and their connections.

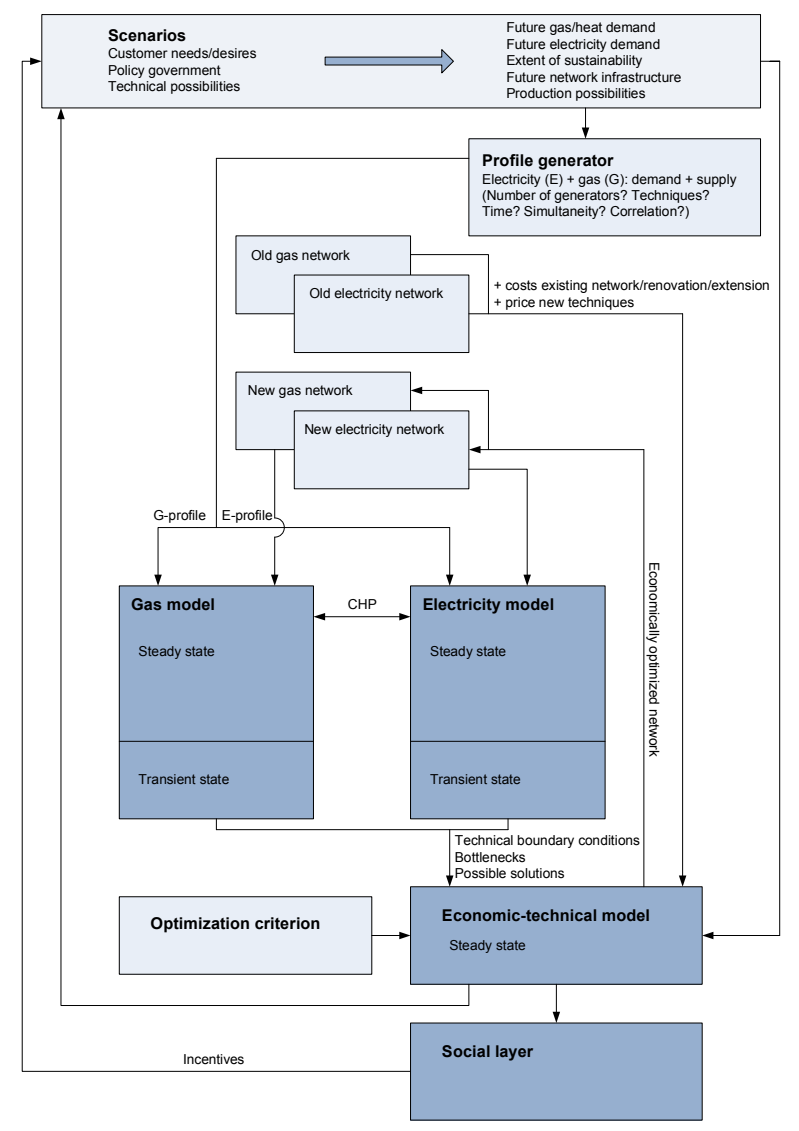

Figure 1. Scheme of concept integrating tools 
The integrating framework includes two detailed technical models (gas and electricity), an economic-technical model and a social layer, connected to each other through scenarios.

In the scenarios possible transition paths will be defined taking into account customer needs, the policy of the government, technical possibilities, which all have their impact on future energy demands, extent of sustainability, future network structure and production possibilities.

The economic tool (economic-technical model) performs an economic optimization taking into account technical constraints and environmental conditions. The global goal of the optimization criterion encloses the particular goals of the different stakeholders. Later on the effects of possible incentives on the stakeholders' behaviour will be studied by means of laboratory experiments (e.g. [2]) as these are crucial for attaining the economic optimum.

The detailed technical models simulate the infrastructure (gas and electricity) of a typical Dutch residential area. They investigate if problems arise (when? where?) in the gas and electricity networks (capacity problems, violation of technical requirements,...) for different scenarios. A profile generator is built to transform scenario data into electricity and gas demand and supply profiles. Investment decisions about the network infrastructure are taken by the economictechnical model, whereas the technical feasibility is checked in the detailed technical models.

\section{SCENARIOS - PATHWAYS FOR TRANSITIONS}

\section{Assumptions}

The test area is a hypothetical but representative Dutch residential area, with 180 houses, 3 flats, 1 school and 1 shopping centre. The years 2020, 2030 and 2050 are taken as reference for the future situation. It is assumed that the electricity demand will increase. Besides an autonomous increase $(0-2 \%$ per year $)$, plug-in vehicles may lead to an additional electricity demand. Insulating houses affects the heat demand. Due to the global warming the heat demand will decrease $(0-2 \%$ per year) and the cooling demand will increase. Assumptions about extension and renovation of the area within the time span are made.

\section{Configurations and implementation scenarios}

Table 1 shows a set of 6 configurations that will be analysed: reference (current situation), micro/mini combined heat and power (CHP), gas heat pump (HP-gas), electrical heat pump (HP-e), central CHP in the residential area (CHP centr.) and solar boiler (SB). They are distinguished by the way the needs for heat, electricity for apparatus, tap water, cooking, cooling and storage are met: gas $(\mathrm{G})$, centrally or decentralised produced electricity (E), heat $(\mathrm{H})$.

For each configuration additional options are considered such as photovoltaic, urban wind, solar boiler, plug-in vehicle.
Table 1. Set of configurations, distinguished by the way the energy needs are met

\begin{tabular}{|l||c|c|c|c|c|c|}
\hline Config. & Heat & Electr. & Tap & Cook & Cool & Storage \\
\hline \hline Ref. & G & $\begin{array}{c}\text { E } \\
\text { centr. }\end{array}$ & G, E & G & E, G & H, E \\
\hline $\begin{array}{l}\mu \text {-CHP } \\
\text { (mini) }\end{array}$ & G & E dec. & G & G & E, G & H, E \\
\hline HP-gas & G & $\begin{array}{c}\text { E } \\
\text { centr. }\end{array}$ & G & G & G & H, E \\
\hline HP-e & E & $\begin{array}{c}\text { E } \\
\text { centr. }\end{array}$ & E & E & E & H, E \\
\hline $\begin{array}{l}\text { CHP } \\
\text { centr. }\end{array}$ & H & $\begin{array}{c}\text { E } \\
\text { centr. }\end{array}$ & H & E & E & H \\
\hline $\begin{array}{l}\text { SB } \\
(50 \%)\end{array}$ & SB & $\begin{array}{c}\text { E } \\
\text { centr. }\end{array}$ & SB & E & E & H \\
\hline
\end{tabular}

For the different configurations and their additional options implementation scenarios are defined concerning introduction time, penetration degree and spread over the area. The implementation scenarios may influence the electricity and gas demand.

Finally successions of configuration options will be coupled to transition paths [3-6].

\section{ELECTRICITY INFRASTRUCTURE: OPTIMIZATION AND FEASIBILITY STUDY}

\section{Approach}

The economic optimization of the infrastructure is performed by the economic tool, taking into account technical constraints and environmental conditions. For an efficient solution of the complex optimization problem (convergence after a limited number of iterations to an economically optimal solution that meets the technical requirements), the economic tool (optimizer) must not only take into account economical data, but the most important technical constraints as well. Therefore an economictechnical model is developed to be included in the optimization tool. The optimization results in an economically optimized network meeting the most important technical constraints. The remaining technical constraints have to be checked by a detailed electricity model. If this model detects remaining technical problems, possible solutions have to be proposed, together with their costs. The economic tool chooses the best alternative or may decide to allow minor problems at a penalty.

Figure 2 clarifies the approach of the technical constraints in the economic-technical and electricity models. Besides the level of technical detail, the models differ in time unit and time horizon.

Compared to existing integrated economic-technical approaches [7-8], this approach includes more details, additional technologies and extensive reliability analysis. In the future, expansions will be made in several directions (technologies, area extension, stochastic model,...). 


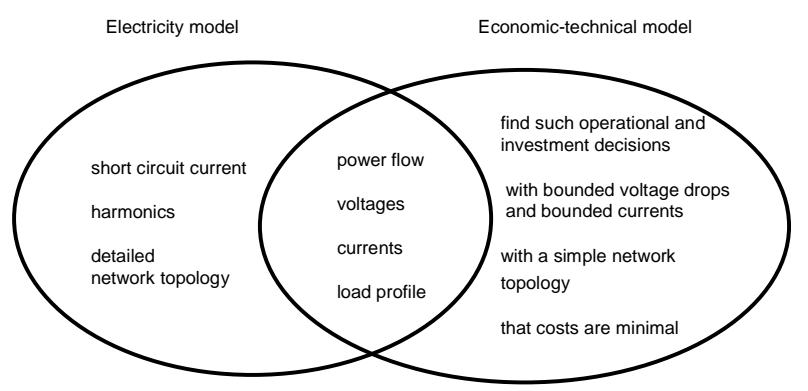

Figure 2. Technical constraints considered in the electricity and the economic-technical models.

\section{Optimization criterion}

The energy demand in the considered area must be met as cheaply as possible, taking into account technical and environmental constraints (e.g. reduction of $\mathrm{CO}_{2}$ emissions). Initially, the supply of a given load at least costs is studied, where future costs are converted to their present values. Subsequently, this model will be refined, possibly including an optimal amount of lost load in cases where the costs of meeting that demand is higher than the associated benefits (the value of lost load).

All costs during the considered time span have to be minimized: investment costs, operational and maintenance costs of network infrastructure and distributed generators, fuel costs, price of electricity obtained from upper grid, costs of $\mathrm{CO}_{2}$ emissions as well as any costs of electricity not supplied.

\section{Characteristics of the electricity infrastructure}

The current electricity infrastructure of the test area is a radial low voltage (LV) network, connected to the upper grid by a $630 \mathrm{kVA} 10 \mathrm{kV} / 400 \mathrm{~V}$ transformer, with ca. 40 households per feeder (cables: Al, $95 \mathrm{~mm}^{2}$ ).

For the future situation, a new infrastructure has to be designed, depending on changing energy needs, availability of new techniques and the policy of the government.

\section{Considered problems of the DNO planner}

Table 2 shows the problems of the DNO planner, sorted by priority to be solved. Network losses are an economical problem and are handled during investment decisions.

Table 2. Problems DNO planner

\begin{tabular}{|l|l|}
\hline Problem & Limits/standards \\
\hline \hline $\begin{array}{l}\text { Overload of network } \\
\text { component } \\
\text { (transformer, cable) }\end{array}$ & Loading > 100\% \\
\hline Voltage characteristics & EN50160, Dutch net code \\
\hline Short circuit currents & Calculated according to IEC60909 \\
\hline $\begin{array}{l}\text { Emission harmonic } \\
\text { currents }\end{array}$ & $\begin{array}{l}\text { IEC61000-3-2, IEC61000-3-12, } \\
\text { IEC61000-3-4 }\end{array}$ \\
\hline Network losses & $\begin{array}{l}\text { Economical assessment } \\
\text { (investment costs vs. operational } \\
\text { costs) }\end{array}$ \\
\hline
\end{tabular}

\section{Economic-technical model}

The economic-technical optimization will be performed using a simulation package: GAMS [9]. As noted above, this will include the most important technical constraints. Also, a simplified network will be used. The technical equations will be validated by simulations in DIgSILENTPowerFactory [10].

\section{Electricity model}

The goal of the electricity model (implemented using DIgSILENT-PowerFactory) is to detect possible problems in the electricity distribution network by introducing new technologies. A limited number of load types will be defined (classified according to voltage dependency, power pick-up, harmonics, flicker), including look up tables with current harmonics as a function of voltage. The electricity network of the test area will be simulated, in steady state and transient modes.

The input of the electricity model consists of

- 5 minute power profiles of loads and generators (provided by the profile generator, taking into account energy needs for heat, apparatus, tap water, ..., weather conditions, house characteristics like insulation, ...)

- The penetration of new technologies (introduction year, spread over the area, evolution of penetration degree)

- Increase/decrease of loads as a function of time (may also be influenced by new technologies)

- Investment decisions

From the electricity model an overview of possible problems is obtained: type of problem, location in the network and time of occurrence.

A preliminary study has been performed [11] where combined heat and power (CHP), photovoltaic (PV) arrays and storage devices (BES) were introduced; designed such that yearly energy demand and supply match as closely as possible in a residential area. In this study about the operational approach of a self-supporting residential area the reverse power flow, voltage levels, system losses, cable and transformer loads were assessed.

Figure 3 shows an example of voltage levels for different seasons and scenarios (average and extreme conditions for supply and demand).

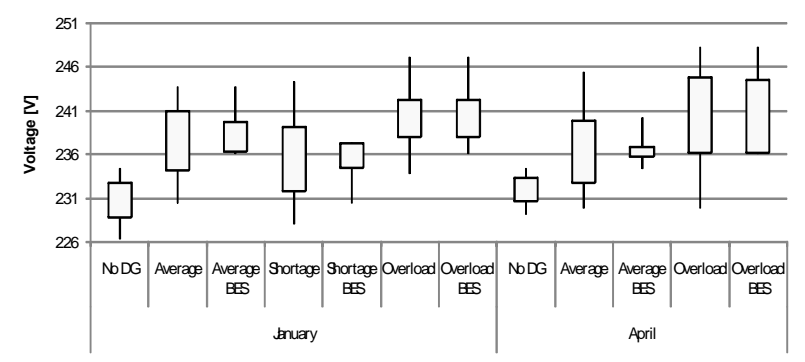

Figure 3. Voltage levels at the end-node of a cable. (The lines represent the range of all simulated values of 15minute-mean-voltage levels throughout a week. The boxes represent the mean value \pm standard deviation.) [11] 
The introduction of distributed generation increases voltage level but it stays within +/- $10 \%$ of the nominal voltage, complying with the Dutch net code or EN50160 standard. BES converges voltage levels. In scenarios with general excess electricity (overload scenario in January and April), BES fails to reduce higher voltage levels.

In general, from the preliminary study it could be learned that the effects of distributed generation in the LV network are promising, though the load flow calculations imply a need for peak load shaving. The storage devices succeeded in minimizing the reverse power flow and transport losses, however storage losses have counter-balanced the effects on transport losses. In scenarios that have to deal with general excess power, storage devices are mostly fully charged and fail to supply peak load shaving, i.e. limiting voltage peaks and transformer loads. This indicates the need for an extra control system.

In the next stage in the development of the detailed electricity model, storage devices with voltage and frequency droop control possibilities will be implemented.

\section{CONCLUSIONS}

Thorough transition studies of energy systems require an integral approach, dealing with technical, economical and social aspects. Within the Dutch EOS-LT program a project is set up to develop new integrating tools based on a multidisciplinary approach by a consortium (TU/e, KEMA, Alliander, Gasunie, CPB, UvA) with combined technical, economical and social expertise. As a result of the first project stage a concept design is made for an integrating simulation tool. Scenarios for possible transition paths for the energy infrastructure of a Dutch residential area are defined. From a preliminary study it could be learned that the effects of distributed generation in the LV network are promising, though control systems supporting peak load shaving may be needed.

In the next project stage the integrating tools will be further implemented, including the modelling of gas infrastructures. Subsequently the tools will be validated by performing simulations and real life experiments in a residential area. The development of integrating tools based on a multidisciplinary approach will make it possible to monitor and evaluate the behaviour and response of actors regarding new systems and they will enable to judge if this new system is a step towards a more sustainable energy system.

The integrating tools will be useful for distribution network planners (confronted with uncertainties about both future energy supply and demand as well as the future role of the grids, different life cycles of network components, ...). Furthermore the project will provide policy makers with insights how to support the transition process.

\section{REFERENCES}

[1] G.A. Bloemhof, F. Combrink, P.T.M. Vaessen, 2007, "Simulation in the energy-infrastructure; FLEXNET, a flexible approach", Proceedings ISAGA, Nijmegen, The Netherlands

[2] R. Aalbers, E. van der Heijden, J. Potters, D. van Soest, H. Vollebergh, 2009, "Technology adoption subsidies: an experiment with managers", Energy Economics, forthcoming

[3] G.J.P. Verbong, F.W. Geels, 2008, "Pathways for sustainability transitions in the electricity sector: Multi-level analysis and empirical illustration", Proceedings Next Generation Infrastructure Conference 'Building networks for a brighter future', Rotterdam, The Netherlands

[4] G. Arts, W. Dicke and L. Hancher (eds.), 2008, "New Perspectives on Investment in Infrastructures", Amsterdam, The Netherlands

[5] Platform Duurzame energievoorziening, Platform Nieuw Gas, 2007, "Naar een duurzame elektriciteitsvoorziening. Aandachtsgebied decentrale infrastructuur", Den Haag, The Netherlands (http://www.senternovem.nl/energietransitiedev/ documentatie/index.asp)

[6] The Dutch Taskforce 'Energietransitie', 2006, "Meer met Energie! Kansen voor Nederland", Den Haag, The Netherlands

[7] W. El-Khattam, Y.G. Hegazy and M.M.A. Salama, 2005, "An integrated distributed generation optimization model for distribution system planning", IEEE Transactions on Power Systems, 20(2), 11581165

[8] S. McCusker and B.F. Hobbs, 2003, "A nested Benders decomposition approach to locating distributed generation in a multi-area power system", Networks and Spatial Economics, 3, 197-223

[9] http://www.gams.com

[10] http://www.digsilent.de

[11] M. Mes, G.M.A. Vanalme, J.M.A. Myrzik, M. Bongaerts, G.J.P. Verbong, W.L. Kling, 2008, "Implementation of Distributed Generation in the Dutch LV Network - Self-Supporting Residential Area", Proceedings International Universities Power Engineering Conference, Padova, Italy 